\title{
Artificial Intelligence and Big Data: The Advent of New Pedagogy in the Adaptive E-Learning System in the Higher Educational Institutions of Saudi Arabia
}

\author{
Mohammed Arshad Khan (D), ${ }^{1}$ Maysoon Khojah, ${ }^{1}$ and Vivek ${ }^{2}$ \\ ${ }^{1}$ College of Administrative and Financial Sciences, Saudi Electronic University, Riyadh-11673, Saudi Arabia \\ ${ }^{2}$ Department of Commerce and Business Studies, Jamia Millia Islamia, New Delhi-110025, India \\ Correspondence should be addressed to Mohammed Arshad Khan; m.akhan@seu.edu.sa
}

Received 22 January 2022; Accepted 3 February 2022; Published 25 February 2022

Academic Editor: Ehsan Namaziandost

Copyright (C) 2022 Mohammed Arshad Khan et al. This is an open access article distributed under the Creative Commons Attribution License, which permits unrestricted use, distribution, and reproduction in any medium, provided the original work is properly cited.

\begin{abstract}
The operations of many industries, such as banking, insurance, energy, healthcare, and retail, have been improved and transformed by the application of artificial intelligence. The education sector is the particular one which has more potential for artificial intelligence and its applications. Universities and colleges are currently facing a number of challenges, including high rates of dropouts and student disengagement in their classes, as well as the failure of traditional learning techniques in the face of ongoing outbreaks. Major issues in the educational sector can be resolved by the proper application of artificial intelligence and big data, which can facilitate learner-centred approaches as per the needs of today's era. This can be better described as a personalised learning approach, in which the needs of each and every student can be considered and education can be provided uniquely for them. In this way, the educator can provide a better learning experience according to the needs and ability of the learners/students. Thus, it also assists in enhancing the motivational level of the learners and minimising the dropout rates of the students. The main purpose of the study is to examine the role of artificial intelligence and big data in the adaption of the E-learning system for imparting better education facilities to the students of various colleges and universities situated in Saudi Arabia. The sample dataset for this study was collected through a purposive sampling technique from the 290 students enrolled in numerous higher educational institutions. The collected data were analysed using SPSS and SmartPLS 3 software. The findings of this study reveal that AI and big data assist educators and students as well to run the teaching and learning process smoothly even in the period of an ongoing pandemic at the higher levels of the education system. It also explores the educational inferences of transpiring technologies in the ways of students' "learning and institutions" teaching and their adaption. In recent eras, technological evolution and an increase in the adoption of latest technologies in the field of higher education have been scouted to forecast the essence of higher education globally in the near future, where AI will be the gist for universities. This study reveals some issues faced by higher educational institutions and students related to the adaptation of these technologies for learning, teaching, administration, and student support. The implications of the present study will be helpful for students and teachers to access educational resources effectively and for educational institutions to improve the efficiency and personalization of learning tasks. Furthermore, it will allow students to get more time with their respective teachers.
\end{abstract}

\section{Introduction}

The emanation of big data, artificial neural networks, machine learning, and cloud computing has allowed technicians to generate an apparatus that can replicate the intelligence of a human. Based on the mentioned technologies, this study refers to the apparatus capable of observing, reacting, learning, recognizing, and resolving issues such as artificial intelligence. These technologies will bring the revolution to workplaces in the near future. Likewise, where artificial intelligence can connect and assist people to execute at their highest levels, this is appearing as 
the upcoming innovative transformation. Many consider AI as a "driver" who is intrinsic to the "Fourth Industrial Revolution," even though it may be the "Fourth Revolution in Education." The school curriculum also has AI as part of it now. Since the E-learning and offline learning methods are different, students' learning evaluation is difficult to do by using offline educational development techniques [1]. E-learning overcomes the issues related to time and space as the number of students is greater and the process of learning and learners' behaviours are complicated. In the traditional method of teaching, the evolution of students was measured by their home assignments' accomplishments and examination results. The students' behaviour in the process of learning cannot be evaluated properly in time. Evaluation in online learning by the use of techniques of "big data analysis" can trace and use data of students related to their learning, which can also be calculated in a scientific way, so that learners' performance can be evaluated timely and accurately [2]. On the one hand, it assists educators in reducing the burden and improving the effect of their teaching; on the other hand, students can have a better understanding of their learning situations, which encourages learning behaviours. Artificial intelligence education evaluation is a vital link in the E-learning process. Through the process of learners' evolution, there could be enhancement to monitoring and feedback of the learning outcomes and improvement in the relative separation of E-learning systems, whereby the students' learning abilities can be intensified. An instruction assists learners to sustain their long-term learning enthusiasm and direct and promote learning and also upgrades the capability of learners to learn freely, thus enhancing the learning standard and shaping learning as a voluntary behaviour. It is also useful for educators and artificial intelligence teaching [3].

As a subset of artificial intelligence, machine learning focuses on developing computer systems that can grasp and adjust to data mechanically [4]. Machine learning algorithms can assist in getting the latest insights, solutions, and predictions to design the requirements and conditions for every individual. The processes of machine learning can obtain precise outcomes and assist in knowledgeable decisionmaking with the accessibility of a vast amount and intense standard of "input training data." $[5,6]$ These "data-intensive" machine learning techniques are situated at the convergence of artificial intelligence and big data and are able to improve the services and efficiency of education, as well as many more areas including government, commerce [7], and science. Artificial intelligence has been growing in the education sector because of its strategic value. As per Loeckx, AI can be used as a potent learning tool which reduces the burdens of teachers and learners, thus assisting students in getting learning experiences effectively $[8,9]$. There are numerous chances for the growth of AI uses in the educational sector; as in recent times, there have been many reforms in different fields such as digital resources, gamification, and personalised learning experiences in the education field. For instance, the modelling prospects of artificial intelligence methods have been utilised consistently to extend adaptive and reactive capabilities for the evolution of "individualized learning" environments as a redress for the inadequacy of educators using the application of "intelligent tutoring systems (ITSs)." Personalized learning experiences are provided by ITSs in four manners: (1) "monitoring students' input," (2) "delivering relevant tasks," (3) "offering effectual feedback," and (4) "applying interface communication between the man and computer." [10]

The teachers have been worried if the application of artificial intelligence challenges their positions. On the contrary, educational practitioners and researchers have been discussing the learning and applications of AI. Some think that development in artificial intelligence would challenge or replace educators as a lot of other jobs have been replaced by automation. Students' perspectives and attitudes towards these changes are also part of the emerging challenges, whereas a number of students who can be considered as "digital citizens" are able to support [11]. However, many experts and scholars in Saudi Arabia and in other countries have embraced a positive outlook for artificial intelligence in education. The implementation of artificial intelligence in education has a long way to mature since AI technology is still growing and evolving [12]. This research propounds the role of the AI teaching system by using big data analysis methods, presuming pertinent researchers for the analysis of learning and general big data techniques [13].

\section{Conceptual Development}

The evolution of AI systems arose in the 1960s and 70s with the growth of heuristic programming techniques and the first neural networks and the establishment of situation control techniques for wide-ranging systems [14]. At present, artificial intelligence has no perfect definition, though it is interpreted on the premises of distinct perspectives of modern science. From the information approach's viewpoint, artificial intelligence is considered an important field of information technology from the main task of intelligent computer systems' development to solve the problems that have been solved by the human mind, such as reasoning, problem-solving, and language understanding [15]. In order to cope with the upcoming opportunities and challenges brought up by the big data wave and artificial intelligence evolution, academicians, policymakers, and educators must be involved in constructive collaboration. We all need to work together to bring up the important competencies and necessary skills in learners. There is a need for joint effort across different disciplines and branches. The aforesaid growth in educational technology and its structured transmission to commercial products will be beneficial to the industry and researchers [16]. Governments and businesses would also benefit from a legislature that prompts technology markets while protecting the data and privacy of users [17]. Prioritizing educational refinement and allowing eminent adoption of a curriculum based on enhanced technology would be fruitful for policymakers and academicians [14]. The implementation and advancements of big data and artificial intelligence technologies in education are driving the development of future trends among policymakers, researchers, and industry stakeholders. Therefore, it 
is necessary to consider "projections and challenges" in the long term [18].

It is important to understand the individual dissimilarities when generating pedagogical tools for targeted individual learners and also to customise education as per individual requirements on various platforms [19]. Accurate and abundant personal data can be collected by intelligent educational systems using AI techniques and big data. Data analytics [20] can identify the learning structures of students and their specific needs. There are research gaps, emerging trends, and disagreements in the merger of big data and AI into educational research. Therefore, in-depth and conscientious knowledge of individual needs is required, which could be utilised to make the learning personalised and at scale and in real time [21].

Commercialization of educational instruments and systems has its own distinctive challenges, as do the academic and scientific aspects of AI and big data in education [22]. A number of countries have endeavoured to stimulate development found on innovation by using intensified technology transmission and encouraging "academia-industry" alliances [23].

\section{Review of the Literature}

The ability to perform several human cognitive tasks on a computer was named "artificial intelligence" by John McCarthy in 1955. These tasks are reasoning, learning, problem-solving, and communicating. Koper and Tattersall [24] explained AI as a title to outline a vast collection of various technologies and algorithms (e.g., machine learning, NLP, data mining, and neural networks). In the former phase, artificial intelligence in education refers to "intelligent tutoring systems," aimed at finding solutions to issues such as increasing operator performance automatically. At present, $\mathrm{AI}$ is described as a technique to use big data to carry out difficult tasks [25].

Though it has been set to progress in the phase of human application evolution, $\mathrm{AI}$ is still in the early stages of unifying AI and education or teaching practices. Koparan [26] examined four types of AI education applications that have caught the attention of various researchers [26]. The "intelligent learning system" can provide "personalized courses" according to students' language, emotional state, knowledge structure, and learning style, as well as some other characteristics to attain the goal of "one person, one lesson schedule" and create a personalised learning atmosphere based on feedback to meet various demands of students. Some "automatic evaluation systems" rest on "natural language processing technologies" such as "Project Essay Grade, e-rater, IntelliMetric, MyAccess, Criterion, and Pianjiao.com" which have been created swiftly, by which correction and homework grading can be acquired quickly. Educational robots are becoming common rapidly in the education field as a powerful tool of learning [27]. Research and analysis on the present scenario and future evolutionary trends of AI education and teaching applications are being conducted by many scholars in China also. Ikedinachi AP and others, for example, have introduced the AI's future and education in the learner model field, as well as discussion and anticipation for the consolidation and teaching model field's applications and certain learning fields [28].

Research on the six disciplines of expert systems such as "robotics, machine learning, natural language understanding, artificial neural networks, and distributed artificial intelligence" had been conducted by the Williams. These have been mostly used in education, and the Williams also discovered their applications in the education area. Burton explored that the present "artificial intelligence + education industry" approach mostly sticks to the severance of the primary educational links and allows technical support in the practise association, development, teaching-learning processes, management processes, and applications [29]. The challenges related to the application of AI education are found on teaching experience, pretentious alliances between government organisations and schools, safety ethics of advanced technology, and technological administration of the well-balanced growth of man-machines [11]. On the contrary, AI has been efficiently applied in the area of special education. It can be helpful to increase the functional efficiency of special people's organs by using technical modes. Their intellectual or physical deficiencies can be improved. It is also worthwhile to complete the requirements of various special people to the extent possible and encourage their personalised learning. Some researchers have also conducted research on the "future trends of the integration of artificial intelligence" and education, resulting in the goals of education, learning techniques, content of education, models of education, educational environments, and resources for education. The role of teachers will also be affected by the further evolution of $\mathrm{AI}$ in the near future [30].

Because of the evolution in these areas [31], various social activities could continue under the pandemic. "Digital tools, platforms, applications," and "communications" among people have given rise to huge amounts of data, i.e., big data, across different areas. The main objective of big data technologies is to utilise the power of vast data in real time or else [32]. Big data analysis provides different technologies and tools, such as data mining, statistical analysis, text analytics, social network analysis, data visualization, machine learning, and signal processing [33].

Learning analytics is "the measurement, collection, analysis, and reporting of data about learners and their contexts, for purposes of understanding and optimising learning and the environments in which it occurs." [34] It is mostly applied to analyse the vast amounts of data. Learning analytics enhances the abilities of AI and machine learning techniques. The necessary information derived from big data can be used to improve administration, learning, and teaching. Therefore, research on AI and big data is gaining more importance in education and psychology [35].

In today's society, numerous industries have applied AI applications for their advancement. This research encircles the concept of AI as it relates to education. Zawacki-Richter et al. [31] categorization of "AIED (artificial intelligence in education) applications" has been used, which are accessible today, such as (a) learner-oriented AIED, (b) instructororiented AIED, and (c) institutional system-oriented AIED. 
Learner-oriented AI assists students in studying a subject domain, i.e., "personalized learning management system." This instructor-oriented tool can be helpful in tasks such as assessments, plagiarism detection, the provision of feedback, and administrative procedures. These systems also assist teachers in monitoring the learning progress of students, and thus, intervention can be imparted energetically. ITS (informational technological system) [36], is a platform that assists students and teachers [37]. AIED has demonstrated its potential to assist students in identifying "knowledge gaps" and obtaining special support, thus relieving educators of routine tasks and assisting them in effectively responding to learners. The end, constructive insights to decision makers and administrators, such as "enrolment and attrition patterns" across different disciplines and universities, can be provided by AIED tools at the level of an institution. The application of AIED has become an important topic of enthusiastic interest among researchers [30].

\section{Hypotheses of the Study}

H01. Artificial intelligence (AI) has a significant direct effect on E-learning

H02. Big data has a significant direct effect on E-learning

H03. Artificial intelligence (AI) has a significant direct effect on higher educational institutions (H.E.I)

H04. Big data has a significant direct effect on higher educational institutions (H.E.I)

H05. E-learning has a significant direct effect on higher educational institutions (H.E.I)

H06. E-learning acts as a mediator between artificial intelligence (AI) and its effect on higher educational institutions (H.E.I)

H07. E-learning acts as a mediator between big data and its effect on higher educational institutions (H.E.I)

\section{Research Methodology}

This research is done through survey methods and is both descriptive and quantitative in nature. There is the use of both primary and secondary data. The method used to collect the data for this research is the questionnaire method. The respondents for this study were students, researchers, scholars, $\mathrm{PhD}$ holders, and faculty members from many higher educational institutions and universities in Saudi Arabia. The questionnaire is made up of two sections: Section-A comprises demographical information of respondents, while Section-B consists of the measurement of the role of $\mathrm{AI}$ and big data in the adaptation of online learning techniques in the institutions of higher education in Saudi Arabia by using the "5-point Likert scale," ranging from "strongly agree-5" to "strongly disagree-1." The questionnaire was prepared using "Google Forms" and was distributed online to the sample respondents from various institutes and colleges of higher education in Saudi Arabia with the help of different social networking sites. Researchers found a total of 295 responses, but only 290 were chosen for the study to facilitate data processing. The statistical tools and techniques used in this study were suitable for further analysis and validated the sample dataset collected from the respondents. Researchers have used "SPSS (v-25)" and "SmartPLS3 software" to analyse the collected data quantitatively. From the point of view of academy experts, the data have also been used for analysis purposes to find out the "future of higher institutions with respect to artificial intelligence" from the point of view of higher educational institutions in Saudi Arabia. The researcher also collected opinions of experts, feedback, and judgements of respondents. The respondents' viewpoints on the openended questions, their feedback, and their choices on multiple choice questions have helped researchers to conclude the direction of artificial intelligence and big data in higher education in the near future.

\section{Findings and Discussion}

The questionnaire comprised 25 questions divided into two sections. One portion dealt with the respondent's demographic characteristics, while the other was separated into four categories: artificial intelligence (AI), big data, E-learning, and higher educational institutions (H.E.I). A summarised approach to the rating scale was applied to the assessable data from participants. It was done on a five-point Likert scale, with "strongly disagree (1)" being the lowest and "strongly agree (5)" being the highest. Researchers found a total of 295 responses, but only 290 were chosen for the study to facilitate data processing. In order to conduct a quantitative analysis of the data, SmartPLS 3 software and SPSS (v-25) were used. This section compromises the research findings and results. The answers and opinions of sample respondents on the survey instrument used in the present study enabled the researchers to conclude the directions of the future scenario of higher education in the light of artificial intelligence.

6.1. Background Information of the Respondents. In this segment, the sample participants of the individuals who filled out the questionnaire are displayed. Table 1 shows the response to the questions pertaining to the demographic factors that were chosen for the study. The information presented here is derived from primary data.

Table 1 denotes the participants' demographic statistics based on their gender, age group, course of study, level of study, and present status. It shows that sample respondents $(65.06 \%)$ were males $(\mathrm{M})$, whereas $37.93 \%$ were females $(\mathrm{F})$. The following details indicate that at least $12.06 \%$ of the total respondents belong to the age group of 18 years and below, $24.13 \%$ fit into the age group of 19-29 years, a majority of $37.93 \%$ belonged to the age group of $30-39$ years, $15.51 \%$ belonged to the age group of 40-49 years, and the remaining $17.241 \%$ fell within the age group of 50-59 years.

The above details indicate that at least $19.65 \%$ of respondents (the total number of courses opted for study) belong to IT (IT, computer science, statistics, and mathematics). Of that total, $28.96 \%$ represents engineering 
TABLE 1: Baseline data of the participants $(N=290)$.

\begin{tabular}{|c|c|c|c|c|}
\hline Basis & Category & Frequency & Cumulative frequency & $\%$ \\
\hline \multirow{2}{*}{ Gender } & Male & 180 & 180 & 65.06 \\
\hline & Female & 110 & 290 & 37.93 \\
\hline \multirow{5}{*}{ Age group } & 18 years and below & 35 & 35 & 12.06 \\
\hline & $19-29$ years & 70 & 105 & 24.13 \\
\hline & $30-39$ years & 110 & 215 & 37.93 \\
\hline & $40-49$ years & 45 & 260 & 15.51 \\
\hline & $50-59$ years & 30 & 290 & 17.241 \\
\hline \multirow{4}{*}{ Course of study } & IT (IT, computer science, statistics, and mathematics) & 57 & 57 & 19.65 \\
\hline & Engineering (agriculture, mechanical, civil, and electrical) & 84 & 141 & 28.96 \\
\hline & Business (accounting, secretarial, supply chain, and marketing) & 60 & 201 & 20.68 \\
\hline & Art and design (fashion and industrial art) & 89 & 290 & 30.68 \\
\hline \multirow{4}{*}{ Level of study } & 1st year & 53 & 53 & 18.27 \\
\hline & 2nd year & 74 & 127 & 25.51 \\
\hline & 3rd year & 61 & 188 & 21.03 \\
\hline & 4th year & 102 & 290 & 35.17 \\
\hline \multirow{3}{*}{ Present status } & On study leave & 70 & 70 & 24.13 \\
\hline & Full-time student & 90 & 160 & 31.03 \\
\hline & Work and school at the same time & 130 & 290 & 44.82 \\
\hline
\end{tabular}

TABLE 2: Mean, SD, and loadings of constructs.

\begin{tabular}{|c|c|c|c|c|}
\hline Construct & Item & Mean & SD & Loading \\
\hline \multirow{4}{*}{ Artificial intelligence (AI) } & AI 1 & 3.78 & 1.129 & 0.81 \\
\hline & AI 2 & 3.43 & 1.040 & 0.88 \\
\hline & AI 3 & 3.97 & 1.033 & 0.82 \\
\hline & AI 4 & 3.84 & 1.119 & 0.81 \\
\hline \multirow{3}{*}{ Big data } & BigData1 & 3.67 & 1.110 & 0.78 \\
\hline & BigData2 & 3.89 & 1.019 & 0.81 \\
\hline & BigData3 & 3.51 & 1.005 & 0.82 \\
\hline \multirow{6}{*}{ E-learning } & E-Learning1 & 3.67 & 1.039 & 0.79 \\
\hline & E-Learning2 & 3.84 & 1.024 & 0.84 \\
\hline & E-Learning3 & 3.81 & 1.218 & 0.87 \\
\hline & E-Learning4 & 3.92 & 1.245 & 0.86 \\
\hline & E-Learning5 & 3.77 & 1.254 & 0.85 \\
\hline & E-Learning6 & 3.86 & 1.171 & 0.83 \\
\hline \multirow{5}{*}{ Higher educational institutions (H.E.I) } & H.E.I 1 & 3.62 & 1.135 & 0.91 \\
\hline & H.E.I 2 & 3.87 & 1.224 & 0.92 \\
\hline & H.E.I 3 & 3.74 & 1.044 & 0.89 \\
\hline & H.E.I 4 & 3.77 & 1.008 & 0.79 \\
\hline & H.E.I 5 & 3.91 & 1.113 & 0.81 \\
\hline
\end{tabular}

(agriculture, mechanical, civil, and electrical), 20.68\% belongs to business (accounting, secretarial, supply chain, and marketing), and the majority of $30.68 \%$ represents art and design (fashion and industrial art).

At least $18.27 \%$ of respondents belong to the 1 st year, $25.51 \%$ belong to the 2 nd year, $21.03 \%$ belong to the 3 rd year, and a majority of $35.17 \%$ represent the 4 th year. Present status represents that at least $24.13 \%$ of respondents are on study leave, $31.03 \%$ are full-time students, and the majority $(44.82 \%)$ is working and attending school at the same time.

6.2. Measurement Model Evaluation. The measuring model was tested using convergent validity, internal consistency, and discriminant validity.
Table 2 represents the mean, standard deviation, and factor loadings of all the constructs used in this study.

In Figure 1, artificial intelligence (AI), big data, E-learning, and higher educational institutions (H.E.I) are represented by circles since they are the latent constructs used by the researchers in the study. Artificial intelligence (AI) is measured through four statement codes as AI 1 to AI 5 , big data is measured through three statement codes as BigData1 to BigData3, E-learning is measured through six statement codes as E-learning1 to E-learning6, and higher educational institutions are represented through codes as H.E.I 1 to H.E.I 5. The factor loading values are shown near the arrows pointing to the respective items/constructs.

Table 3 clearly shows that all the four constructs (AI, big data, E-learning, and H.E.I) met the required thresholds' 


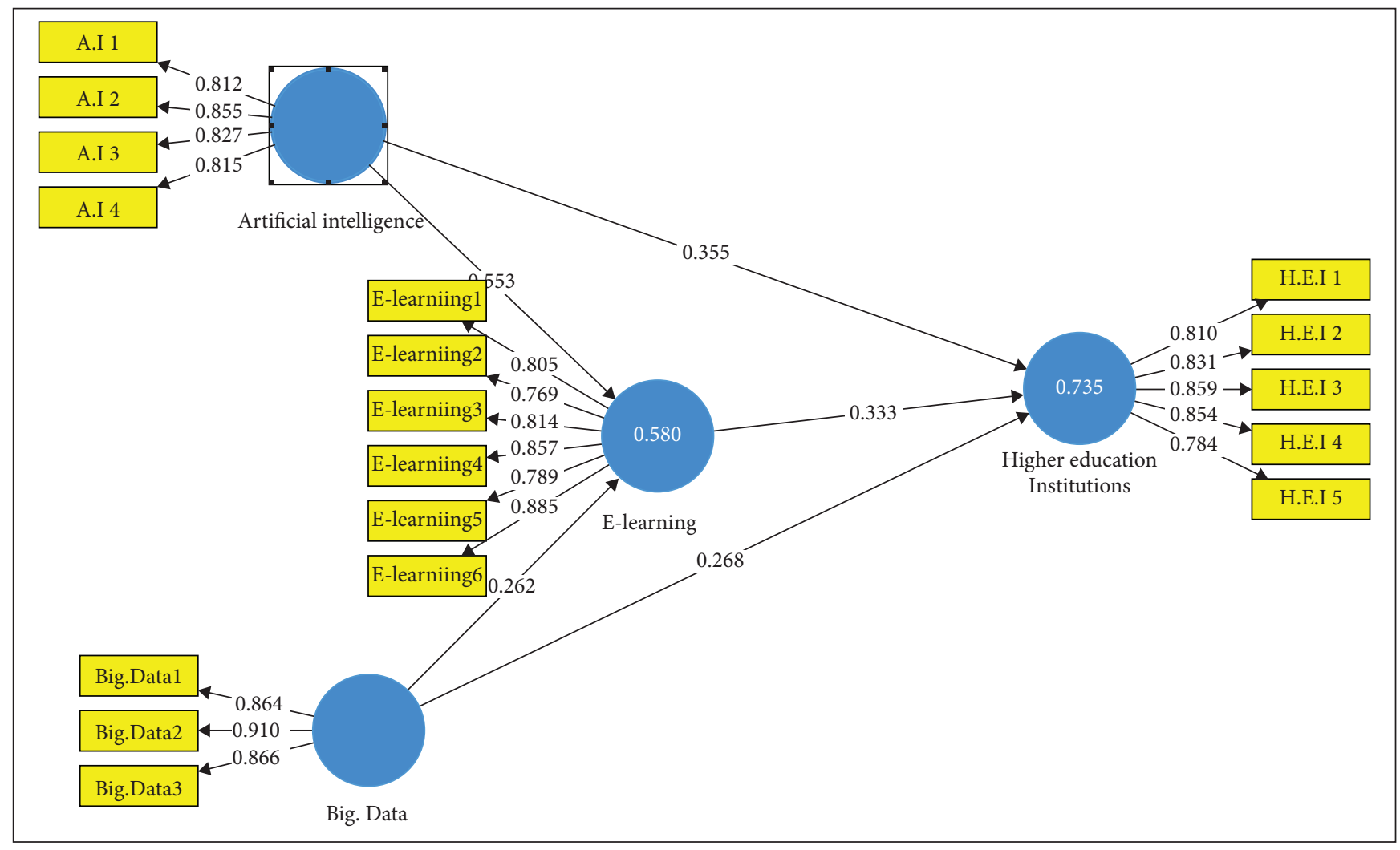

Figure 1: Measurement model from SmartPLS 3.

TABLE 3: Convergent validity result.

\begin{tabular}{lcccc}
\hline Factor & Cronbach's alpha & Rho-A & CR & AVE \\
\hline AI & 0.847 & 0.850 & 0.897 & 0.685 \\
Big data & 0.855 & 0.860 & 0.912 & 0.775 \\
E-learning & 0.903 & 0.907 & 0.925 & 0.674 \\
H.E.I & 0.885 & 0.885 & 0.916 & 0.685 \\
\hline
\end{tabular}

limit as the value of composite reliability (CR) was above 0.7 , and "average variance extracted" (AVE) exceeded 0.5 [38]. The value of "Cronbach's alpha" and rho-A value establish "internal consistency" was also greater than 0.7 [39]. Therefore, the convergent validity of the (AI, big data, E-learning, H.E.I) constructs was proved [40].

6.3. Discriminant Validity Result. The Fornell-Larcker and cross-loading criteria were examined to check the discriminant validity. "Discriminant validity criterion indicates the extent to which the measure is adequately distinguishable from related constructs within the theoretical framework."

Table 4 shows the Fornell-Larcker criterion; in this criterion, you take the "square roots of average variance extracted" of the available constructs. The values were as follows: AI (0.828), big data (0.880), E-learning (0.821), and H.E.I (0.828), which were higher than the correlation values between each construct and all other constructs. Thus, discriminant validity was established as per the Fornell-Larcker criterion [41].
TABLE 4: Discriminant validity-Fornell-Larcker criterion.

\begin{tabular}{lcccr}
\hline Factors & AI & Big data & E-learning & H.E.I \\
\hline AI & 0.828 & & & \\
Big data & 0.710 & 0.880 & & \\
E-learning & 0.739 & 0.655 & 0.821 & \\
H.E.I & 0.791 & 0.738 & 0.771 & 0.828 \\
\hline
\end{tabular}

Table 5 represents the cross-loading criterion in which all constructs (AI, big data, E-learning, and H.E.I) loadings were higher than cross-loadings with other constructs across the columns. Thus, discriminant validity was ascertained as per the cross-loading criterion [42].

Table 6 depicts the heterotrait-monotrait (HTMT) values for all the constructs (AI, big data, E-learning, and H.E.I) were below the recommended value of 0.9 [42]. Thus, there is an establishment of measurement model's discriminant validity.

6.4. Structural Model Evaluation. Whenever evaluating the structural model, "multicollinearity" needs to be examined to ensure whether the results are valid. The "variance inflation factor (VIF)" values ranged from 2.33 to 3.252 , indicating that the model lacked multicollinearity [43]. Following this, the structural model was tested using the bootstrapping approach (3000 resamples) to determine the relevance of the hypotheses.

In Figure 2, the PLS-SEM model reveals that whenever the $t$-values are more than the prescribed limit of 1.96 for the 
TABLE 5: Discriminant validity-loading and cross-loading criterion.

\begin{tabular}{lcccc}
\hline Factor & AI & Big data & E-learning \\
\hline AI 1 & 0.812 & 0.585 & 0.570 & 0.668 \\
AI 2 & 0.855 & 0.649 & 0.589 & 0.580 \\
AI 3 & 0.827 & 0.568 & 0.613 & 0.658 \\
AI 4 & 0.815 & 0.547 & 0.551 & 0.623 \\
Bigdata1 & 0.597 & 0.864 & 0.640 & 0.744 \\
Bigdata2 & 0.660 & 0.910 & 0.531 & 0.672 \\
Bigdata3 & 0.616 & 0.866 & 0.805 & 0.592 \\
E-Learning1 & 0.636 & 0.559 & 0.769 & 0.632 \\
E-Learning2 & 0.546 & 0.450 & 0.814 & 0.564 \\
E-Learning3 & 0.569 & 0.470 & 0.857 & 0.789 \\
E-Learning4 & 0.653 & 0.636 & 0.885 & 0.665 \\
E-Learning5 & 0.532 & 0.509 & 0.618 \\
E-Learning6 & 0.688 & 0.582 & 0.612 \\
H.E.I 1 & 0.670 & 0.608 & 0.657 \\
H.E.I 2 & 0.616 & 0.542 & 0.638 \\
H.E.I 3 & 0.648 & 0.624 & 0.675 \\
H.E.I 4 & 0.648 & 0.650 & 0.810 \\
H.E.I 5 & 0.687 & 0.622 & 0.831 \\
\hline
\end{tabular}

TABLE 6: Discriminant validity—heterotrait-monotrait criterion.

\begin{tabular}{|c|c|c|c|c|}
\hline Factors & $\mathrm{AI}$ & Big data & E-learning & H.E.I \\
\hline \multicolumn{5}{|l|}{ AI } \\
\hline Big data & 0.834 & & & \\
\hline E-learning & 0.840 & 0.739 & & \\
\hline H.E.I & 0.833 & 0.844 & 0.849 & \\
\hline
\end{tabular}

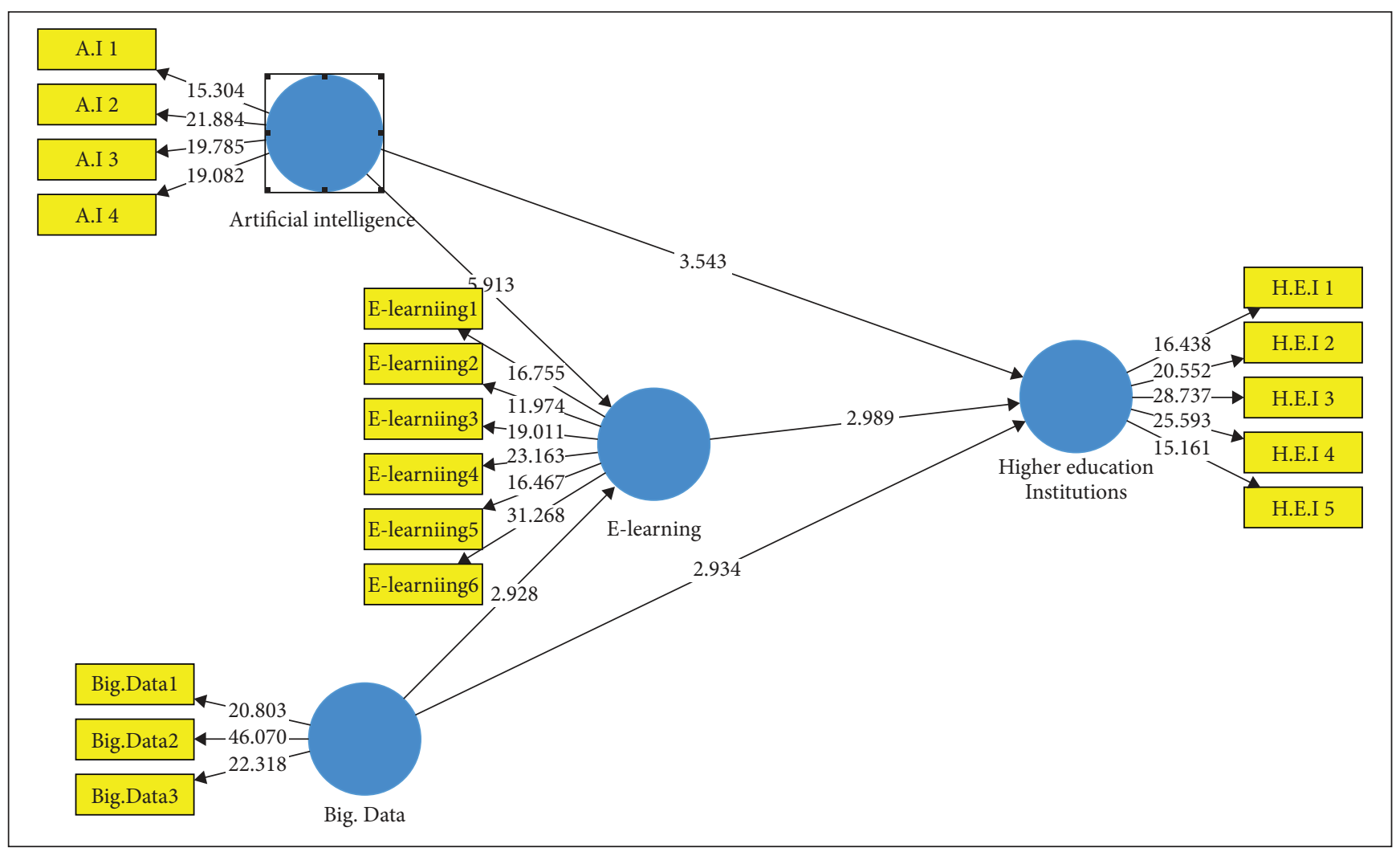

FIGURE 2: Structural equation model (SEM). 
TABLE 7: Direct impact of AI and big data and hypothesis testing.

\begin{tabular}{lccccc}
\hline Hypothesis & Path & $\beta$ & $t$-value & $p$ value & Result \\
\hline H01 & AI $\longrightarrow$ E-learning & 0.551 & 6.053 & $<0.001$ & Supported \\
H02 & Big data $\longrightarrow$ E-learning & 0.260 & 2.829 & $<0.001$ & Supported \\
H03 & AI $\longrightarrow$ H.E.I & 0.343 & 3.523 & $<0.001$ & Supported \\
H04 & Big data $\longrightarrow$ H.E.I & 0.265 & 2.975 & $<0.001$ & Supported \\
H05 & E-learning $\longrightarrow$ H.E.I & 0.346 & 2.955 & $<0.001$ & Supported \\
\hline
\end{tabular}

TABLE 8: Mediation effect or indirect effect of E-learning and hypothesis testing.

\begin{tabular}{lccccc}
\hline Hypothesis & Path & $\beta$ & $t$-value & $p$ value & Result \\
\hline H06 & AI $\longrightarrow$ E-learning $\longrightarrow$ H.E.I & 0.192 & 2.520 & $<0.001$ & Supported \\
H07 & Big data $\longrightarrow$ E-learning $\longrightarrow$ H.E.I & 0.087 & 1.645 & $>0.05$ & Not supported \\
\hline
\end{tabular}

regression weights, the conclusion is that each path is significant at the 5 percent significance level or better (i.e., the estimated path parameter is significant). The outcomes extracted from the SEM model are exhibited in Tables 7 and 8.

Table 7 shows that hypotheses $\mathrm{H} 01, \mathrm{H} 02, \mathrm{H} 03, \mathrm{H} 04$, and $\mathrm{H} 05$ were supported in this study. H01 denotes a direct and positive relationship between artificial intelligence and E-learning $(\beta=0.551, t$-value $=6.053$, and $p$ value $<0.001)$. Simultaneously, H02 indicates a direct and positive relationship between big data and E-learning $(\beta=0.260, t$-val$\mathrm{ue}=2.829$, and $p$ value $<0.001)$. H03, on the contrary, demonstrates a direct and positive relationship between $\mathrm{AI}$ and H.E.I $(\beta=0.343, t$-value $=3.523$, and $p$ value $<0.001)$. Similarly, H04 demonstrates that big data has a direct and positive relationship with H.E.I $(\beta=0.264, t$-value $=2.975$, and $p$ value $<0.001)$. Lastly, H05 represents that E-learning is related to the H.E.I in a direct and positive way $(\beta=0.34, t$-value $=2.955$, and $p$ value $<0.001$ )

Table 8 shows that E-learning supported hypothesis H06, demonstrating a mediation or indirect effect on H.E.I $(\beta=0.192, t$-value $=2.520$, and $p$ value $<0.001)$. However, H07 was not supported, and E-learning had no mediation or indirect effect on HE.I $(\beta=0.087, t$-value $=1.645$, and $p$ value $>0.05$ ).

\section{Implications of the Study}

According to the findings of the current study, higher education will undergo significant changes as a result of the need to adapt to new generational techniques and find new funding sources. Higher education is notoriously conservative, so introducing a few alterations to the institutions and the way teaching is taught could prove to be a positive development. Emerging technologies and their impact on student learning and educational institutions are the focus of this study. The rapid adoption of new technologies in higher education in a world where artificial intelligence and big data are part of the fabric of our universities is being examined in order to predict the future nature of higher education.

\section{Limitations and Future Scope of the Study}

The following are the limitations of this study and their future scope: the first limitation is that the majority of sample respondents came from urban areas, whereas rural areas may have a different educational scenario. As a result, the study's generalizability is limited as it is limited to urban educational institutes or universities. Second, purposive sampling was used as the nonprobability sampling method, so the generalizability of the findings is low. Third, we discussed only one mediator variable, that is, E-learning, while other settings might exist to be considered. Any other suitable moderating variable may be introduced through which artificial intelligence and big data affect the learning pattern of higher educational institutions.

Future research should assess educational institutions' or universities' digital pedagogy and connect it to students and faculty, thereby accelerating the adoption of artificial intelligence and big data. Additionally, we take a qualitative approach to studying E-learning or employ a variety of methods and data types to conduct research on this subject.

\section{Conclusion}

Educators must have an understanding of the proper utilisation of artificial intelligence methods for the academic achievements of students. This research study has four main dimensions in it: artificial intelligence (AI), big data, E-learning, and higher educational institutions (H.E.I). The AI teaching system, which is based on big data, assists learners to learn independently by creating a suitable environment. The AI teaching system allows students to learn outside the boundaries of time and space in higher educational institutions. In contrast, E-learning cannot assist teachers to better understand students as the AI teaching system creates distance between teachers and students, and an educator has to deal with many students at the same time. Paying attention to every student's learning progress is difficult as the teachers cannot perform like in the traditional teaching system. However, teachers try to understand and observe the learning situation and process of every learner. They provide students with proper guidance to improve their learning competence. Therefore, it has been essential to apply big data analysis techniques in E-learning to overcome these issues. The learning situations of students can be evaluated, assessed, and analysed using collected student learning data.

The issues such as teaching on time, better learning efficiency, and improvement in students' performance can 
be resolved by providing the proper guidance after evaluating and understanding the students' learning situations. AI and big data assist teachers in evaluation to gain these objectives of online learning in higher educational institutions for improving teaching effects. E-learning evaluation is necessary to provide students with adaptive teaching and is also helpful for teachers for personalised teaching in higher educational institutions in Saudi Arabia. E-learning is a continuous, diverse, and complex behaviour that needs a detailed study of online learning behaviour to evaluate AI teaching. The scope of research and the relevant scope of AI teaching evaluation are widespread at present. To make the teaching process more efficient, it would be beneficial to have more in-depth research on E-learning evaluation to increase the efficiency of the teaching process in higher educational institutions. The findings of this study show that AI and big data help educators and students run the teaching and learning process smoothly even in the period of an ongoing pandemic at the higher levels of the education system. The outcomes of this research will be useful for educational AI developers, researchers, and students. The applications of big data and $\mathrm{AI}$ in the teaching process are yet onset and limited by challenges such as technology and standpoint. Nevertheless, the convergence of growth in computer science, psychology, and data science manifests prominent promise in transforming educational research and practice. It is anticipated that the current attainments and future recommendations introduced in the paper would be helpful to the objective of helping learners and teachers seek continuous growth.

\section{Data Availability}

The data used to support the findings of this study are available from the corresponding author upon request.

\section{Consent}

Informed consent was obtained from the respondents of the survey.

\section{Conflicts of Interest}

The authors declare no conflicts of interest.

\section{Acknowledgments}

The authors extend their appreciation to the Deputyship for Research and Innovation, Ministry of Education, Saudi Arabia, for funding this research work through Project no. 7992.

\section{References}

[1] M. I. Jordan and T. M. Mitchell, "Machine learning: trends, perspectives, and prospects," Science, vol. 349, no. 6245, pp. 255-260, 2015.

[2] J. D. Gobert, M. A. S. Pedro, R. S. J. d Baker, E. Toto, and O. Montalvo, "Leveraging educational data mining for realtime performance assessment of scientific inquiry skills within microworlds," JEDM-Journal of Educational Data Mining, vol. 4, no. 1, pp. 111-143, 2012.

[3] S. Joshi, R. K. Rambola, and P. Churi, "Evaluating artificial intelligence in education for next generation," Journal of Physics: Conference Series, vol. 1714, no. 1, 2021.

[4] J. W. Pellegrino and M. L. Hilton, Education for Life and Work: Developing Transferable Knowledge and Skills in the 21st CenturyNational Academies Press, Washington, DC, USA, 2012.

[5] H. N. Alshareef, A. Majrashi, M. Helal, and M. Tahir, "Knowledge extraction and data visualization: a proposed framework for secure decision making using data mining," International Journal of Advanced Computer Science and Applications (IJACSA), vol. 12, no. 8, pp. 483-489, 2021.

[6] L. Darling-Hammond, L. Flook, C. Cook-Harvey, B. Barron, and D. Osher, "Implications for educational practice of the science of learning and development," Applied Developmental Science, vol. 24, no. 2, pp. 97-140, 2020.

[7] M. A. Khan, A. Tiwari, T. Sharma, M. R. Farooqi, and M. Tahir, "Artificial intelligence in commerce and business to deal with COVID-19 pandemic," Turkish Journal of Computer and Mathematics Education (TURCOMAT), vol. 12, no. 13, pp. 1748-1760, 2021.

[8] K. Colchester, H. Hagras, D. Alghazzawi, and G. Aldabbagh, "A survey of artificial intelligence techniques employed for adaptive educational systems within e-learning platforms," Journal of Artificial Intelligence and Soft Computing Research, vol. 7, no. 1, pp. 47-64, 2017.

[9] A. W. Muzaffar, M. Tahir, M. W. Anwar, Q. Chaudry, S. R. Mir, and Y. Rasheed, "A systematic review of online exams solutions in E-learning: techniques, tools, and global adoption," IEEE Access, vol. 9, pp. 32689-32712, 2021.

[10] H. Luan, P. Geczy, H. Lai et al., "Challenges and future directions of big data and artificial intelligence in education," Frontiers in Psychology, vol. 11, pp. 1-11, Article ID 580820, 2020.

[11] M. A. Khan, V. Vivek, M. Khojah, M. K. Nabi, M. Paul, and S. M. Minhaj, "Learners' perspective towards e-exams during COVID-19 outbreak: evidence from higher educational institutions of India and Saudi Arabia," International Journal of Environmental Research and Public Health, vol. 18, no. 12, Article ID 6534, 2021.

[12] Z. T. Zhu, M. H. Yu, and P. Riezebos, "A research framework of smart education," Smart Learning Environments, vol. 3, no. 1, p. 4, 2016.

[13] M. Ali, A. Hussein, and H. K. M. Al-Chalabi, "Pedagogical agents in an adaptive E-learning system," SAR Journal-Science and Research, vol. 3, no. 1, pp. 24-30, 2020.

[14] M. A. Khan, T. Kamal, A. Illiyan, and M. Asif, "School students' perception and challenges towards online classes during COVID-19 pandemic in India: an econometric analysis," Sustainability (Switzerland), vol. 13, no. 9, pp. 1-15, 2021.

[15] J. D. Gobert, Y. J. Kim, M. A. Sao Pedro, M. Kennedy, and C. G. Betts, "Using educational data mining to assess students' skills at designing and conducting experiments within a complex systems microworld," Thinking Skills and Creativity, vol. 18, pp. 81-90, 2015.

[16] S. J. H. Yang, H. Ogata, T. Matsui, and N.-S. Chen, "Humancentered artificial intelligence in education: seeing the invisible through the visible," Computers and Education: Artificial Intelligence, vol. 2, Article ID 100008, 2021.

[17] M. S. Siddiqui, U. A. Siddiqui, M. A. Khan, I. G. Alkandi, A. K. Saxena, and J. H. Siddiqui, "Creating electronic word of mouth credibility through social networking sites and 
determining its impact on brand image and online purchase intentions in India," Journal of Theoretical and Applied Electronic Commerce Research, vol. 16, no. 4, pp. 1008-1024, 2021.

[18] C. Coman, L. G. $\square$ îru, L. Meseşan-Schmitz, C. Stanciu, and M. C. Bularca, "Online teaching and learning in higher education during the coronavirus pandemic: students' perspective," Sustainability (Switzerland), vol. 12, no. 24, pp. 1-22, 2020.

[19] A. Jaiswal and C. J. Arun, "Potential of artificial intelligence for transformation of the education system in India," International Journal of Education and Development using Information and Communication Technology, vol. 17, no. 1, pp. 142-158, 2021.

[20] S. C. Tsai, C. H. Chen, Y. T. Shiao, J. S. Ciou, and T. N. Wu, "Precision education with statistical learning and deep learning: a case study in Taiwan," International Journal of Educational Technology in Higher Education, vol. 17, no. 1, p. 12, 2020.

[21] M. E. Webb, A. Fluck, J. Magenheim et al., "Machine learning for human learners: opportunities, issues, tensions and threats," Educational Technology Research \& Development, vol. 69, no. 4, pp. 2109-2130, 2021.

[22] K. Ahmad, J. Qadir, A. Al-Fuqaha et al., "Artificial intelligence in education: a panoramic review," 2020.

[23] E. G. Mense, P. A. Lemoine, C. J. Garretson, and M. D. Richardson, "The development of global higher education in a world of transformation," Journal of Education and Development, vol. 2, no. 3, p. 47, 2018.

[24] R. Koper and C. Tattersall, "New directions for lifelong learning using network technologies," British Journal of Educational Technology, vol. 35, no. 6, pp. 689-700, 2004.

[25] M. A. Khan, "Netizens' perspective towards electronic money and its essence in the virtual economy: an empirical analysis with special reference to Delhi-NCR, India," Complexity, vol. 2021, Article ID 7772929, 18 pages, 2021.

[26] T. Koparan, "The effect of project based learning on the statistical literacy levels of student 8th grade," European Journal of Educational Research, vol. 3, no. 3, pp. 145-157, 2014.

[27] P. M. Moreno-Marcos, C. Alario-Hoyos, P. J. Munoz-Merino, and C. D. Kloos, "Prediction in MOOCs: a review and future research directions," IEEE Transactions on Learning Technologies, vol. 12, no. 3, pp. 384-401, 2019.

[28] A. Renz and R. Hilbig, "Prerequisites for artificial intelligence in further education: identification of drivers, barriers, and business models of educational technology companies," International Journal of Educational Technology in Higher Education, vol. 17, no. 1, 2020.

[29] E. Scarmozzino, V. Corvello, and M. Grimaldi, "Entrepreneurial learning through online social networking in high-tech startups," International Journal of Entrepreneurial Behaviour \& Research, vol. 23, no. 3, pp. 406-425, 2017.

[30] C. Guan, J. Mou, and Z. Jiang, “Artificial intelligence innovation in education: a twenty-year data-driven historical analysis," International Journal of Innovation Studies, vol. 4, no. 4, pp. 134-147, 2020.

[31] S. Habib, N. N. Hamadneh, and M. A. Khan, "Influence of electronic word of mouth (Ewom) and relationship marketing on brand resonance: a mediation analysis," Sustainability (Switzerland), vol. 13, no. 12, 2021.

[32] O. Zawacki-Richter, V. I. Marín, M. Bond, and F. Gouverneur, "Systematic review of research on artificial intelligence applications in higher education-where are the educators?"
International Journal of Educational Technology in Higher Education, vol. 16, no. 1, 2019.

[33] U. Sivarajah, M. M. Kamal, Z. Irani, and V. Weerakkody, "Critical analysis of Big Data challenges and analytical methods," Journal of Business Research, vol. 70, pp. 263-286, 2017.

[34] B. K. Daniel, "Big Data and data science: a critical review of issues for educational research," British Journal of Educational Technology, vol. 50, no. 1, pp. 101-113, 2019.

[35] X. Zhai, X. Chu, C. S. Chai et al., "A review of artificial intelligence (AI) in education from 2010 to 2020," Complexity, vol. 2021, Article ID 8812542, 18 pages, 2021.

[36] B. Xu, "Artificial intelligence teaching system and data processing method based on big data," Complexity, vol. 2021, Article ID 9919401, 11 pages, 2021.

[37] M. Chassignol, A. Khoroshavin, A. Klimova, and A. Bilyatdinova, "Artificial Intelligence trends in education: a narrative overview," Procedia Computer Science, vol. 136, pp. 16-24, 2018.

[38] J. F. Hair Jr., G. T. M. Hult, C. Ringle, and M. Sarstedt, Handbook of Market Research, Springer, Cham, Switzerland, 2020.

[39] A. Adepoju and A. Adeniji, "Technology acceptance of E-banking services in an unnatural environment," SEISENSE Journal of Management, vol. 3, no. 3, pp. 34-50, 2020.

[40] H. Khanifar, M. J. Mohaghegh Nia, G. Jandaghi, Z. Molavi, and M. Emami, "Factors influencing the intendancy of E-banking: an integration of TAM \& TPB with eservice quality," Journal of Applied Sciences Research, vol. 8, no. 3, pp. 1842-1852, 2012.

[41] Fornell and Lacker, "Discriminant validity assessment: use of Fornell \& Larcker criterion versus HTMT criterion," Journal of Physics: Conference Series PAPER, vol. 890, no. 1, pp. 1-6, Article ID 012163, 1981.

[42] J. Henseler, C. M. Ringle, and M. Sarstedt, "A new criterion for assessing discriminant validity in variance-based structural equation modeling," Journal of the Academy of Marketing Science, vol. 43, no. 1, pp. 115-135, 2014.

[43] M. O. Akinwande, H. G. Dikko, and S. Agboola, "Variance inflation factor: as a condition for the inclusion of suppressor variable(s) in regression analysis," Open Journal of Statistics, vol. 5, no. 7, pp. 754-767, 2015. 